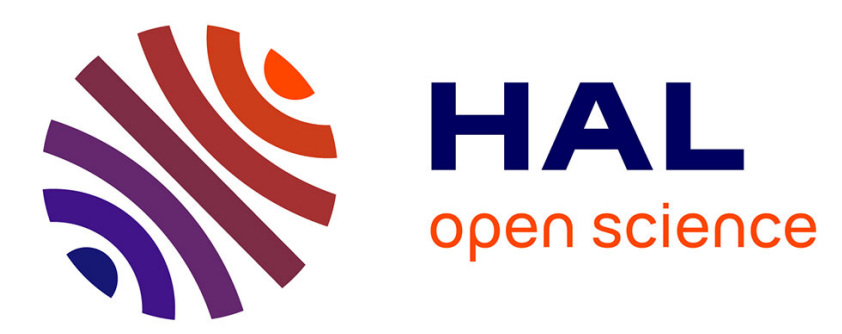

\title{
Effect of roll compactor sealing system designs: A finite element analysis
}

\author{
Alon Mazor, Lucia Perez-Gandarillas, Alain de Ryck, Abderrahim Michrafy
}

\section{To cite this version:}

Alon Mazor, Lucia Perez-Gandarillas, Alain de Ryck, Abderrahim Michrafy. Effect of roll compactor sealing system designs: A finite element analysis. Powder Technology, 2016, 289, pp.21-30. 10.1016/j.powtec.2015.11.039 . hal-01609015

\section{HAL Id: hal-01609015 https://hal.science/hal-01609015}

Submitted on 15 Mar 2019

HAL is a multi-disciplinary open access archive for the deposit and dissemination of scientific research documents, whether they are published or not. The documents may come from teaching and research institutions in France or abroad, or from public or private research centers.
L'archive ouverte pluridisciplinaire HAL, est destinée au dépôt et à la diffusion de documents scientifiques de niveau recherche, publiés ou non, émanant des établissements d'enseignement et de recherche français ou étrangers, des laboratoires publics ou privés. 


\title{
Effect of roll compactor sealing system designs: A finite element analysis
}

\author{
Alon Mazor *, Lucia Perez-Gandarillas, Alain de Ryck, Abderrahim Michrafy \\ Université de Toulouse, Mines Albi, CNRS, Centre RAPSODEE, Albi, France
}

\begin{abstract}
A B S T R A C T
In the pharmaceutical industry, the roll compaction is part of the dry granulation process, densifying fine powders into ribbons that will be later milled to produce granules with good flowability for subsequent die compaction process. Roll compactors are constructed with a sealing system, limiting the loss of powder from the sides. However, the sealing system may result in unwanted non-uniformity of the ribbon's properties. In this work, a 3D Finite Elements Method (FEM) modeling is used to analyze the roll compaction process and the effect of sealing system designs on the compacted ribbon's density distribution. A density dependent Drucker-Prager Cap (DPC) constitutive model for microcrystalline cellulose (Avicel PH-101) was calibrated and implemented in Abaqus/Explicit. Two different FEM models were investigated, one with a fixed side sealing called cheek plates and another where the side sealing is integrated with the bottom roll called rimmed-roll. Both numerical and experimental results clearly show the non-uniform roll pressure and density distribution for the cheek plates assembly, whereas the rimmed-roll shows an overall more uniformly distributed resultant pressure and density distribution. These results demonstrate the capability of FEM modeling to provide insight and help achieving a better understanding of the roll compaction process.
\end{abstract}

Keywords:

Roll compaction

Finite Elements Method

Drucker-Prager Cap model

Density distribution

Rimmed-roll

\section{Introduction}

In the pharmaceutical industry, the roll compaction process is used for dry granulation, densifying fine powders into large dense granular thus improving flowability for direct compression, avoiding segregation in the powder mix and minimizing dust problems [1]. Densifying the powder is done by passing between two counter-rotating rolls, which applies mechanical pressure on the powder. The friction between the feed material and roll surface pushes the powder to a narrow gap, where the powder is subjected to high stresses leading to the formation of compacted ribbons. The roll pressure in the gap region during roll compaction process has the most significant impact on the porosity of the ribbons. Ribbon's density, i.e., solid fraction, is one of the critical quality parameter of roll compaction process that influences the compactibility of granules during tablet formation. The roll compaction system design and operating conditions have a direct effect on the produced compacted ribbon's quality. In order to ensure the consistency, repeatability and quality of the final dosage form, it is important to ensure the quality and avoid heterogeneity of the produced ribbon.

The roll compactors are constructed with a sealing system, limiting the loss of powder from the sides [1,2]. However, the sealing system may result in unwanted non-uniform properties along the ribbon's width and may also exhibit fractured or incomplete compacted edges. Numerous experimental studies were conducted in order to evaluate

\footnotetext{
* Corresponding author.

E-mail address: alon.mazor@mines-albi.fr (A. Mazor).
}

the density distribution of roll compacted ribbons using destructive and non-destructive methods. The studies were conducted on pharmaceutical powders using laboratory roll compactors integrated with fixed side seals (cheek plates), evaluating the density distribution by ultrasonic[3], micro-indentation[4], X-ray tomography [3,4], near infrared chemical imaging $[5,6]$ and pressure gauges[7,8]. Results showed non-uniformity along the ribbon's width with lower densification at the edges and higher at the middle of the produced ribbon. Moreover, cheek plates may also have a negative effect on the ribbon with fractured or incomplete compacted edges.

Funakoshi [9] developed a roll compactor with concave-convex roll pair in order to avoid the loss of powder and to reduce the ribbon's heterogeneity. The compaction pressure distribution obtained for convaco-convex rolls showed an overall uniform distribution compared to the flat rolls which obtained higher compaction pressure at the middle and lower at the edges. Based on the same mechanics, several roll compactors offers a rimmed-roll sealing system in order to reduce the cheek plates unwanted effects.

Over the past two decades, Finite Elements Method (FEM) modeling were adopted and further developed to simulate pharmaceutical forming processes. FEM models of powder roll compaction process which started considering a plane strain two-dimensional case [10-12], founded to be comparable and more accurate than the one-dimensional analytical Johanson [13] and Slab method[14,15] models. With the increasing computational power in the last years, the development of three-dimensional models provided greater insight on the pressure and density distribution during the roll compaction processes[16,7,17]. Wang et al. [18] found a 
variation in the local density for different sealing system using FEM models, however, this numerical study was not fully investigated nor validated experimentally.

The aim of this work is to investigate by FEM modeling the roll compaction process using both rimmed-roll and cheek plates sealing system design. FEM models may give further insight and help understand the mechanics of complex processes such as the roll compaction process. The simulation results are compared with experimentally measured density distribution of the produced ribbons in order to validate the FEM models.

\section{Materials and methods}

\subsection{Roll compaction design and process parameters}

The ribbons were produced in this work by Gerteis roll compactor: Mini-pactor 250/25 (Gerteis Machinen + Process engineering AG, Jona, Switzerland). The Gerteis Mini-pactor roll compactor has two possible assemblies for side sealing: cheek plates or rimmed-roll as can be seen in Fig. 1. The most commonly used sealing system is the cheek plates (i.e. fixed side seals), which are fixed and positioned in between the rolls. In order to avoid the problems caused by cheek plates, the Gerteis Mini-pactor also offers a rimmed-roll sealing system. The rimmed-roll is basically a ring, which is mounted on the bottom roll and acts as a sealing in the compaction region. The process parameters set were a controlled gap mode for $1.5 \mathrm{~mm}$, roll speed of $2 \mathrm{rpm}$ and $4 \mathrm{kN} / \mathrm{cm}$ roll separation force. The rolls chosen are knurled rolls.

\subsection{Powder}

The powder used in this work is the microcrystalline cellulose (Avicel PH 101, FMC BioPolymer, Philadelphia, PA, USA). The MCC is one of the most important and widely used excipient in the pharmaceutical industry. It has excellent compressibility properties and used as diluent for drug formulations in the tableting process[19,20]. Tablets with MCC show high strength and on the other hand disintegrate quickly. The true density of the powder blend was determined using a helium pycnometer (Accupyc 1330, Micromeritics Instrument Corp., Norcross, GA, USA) as $\rho_{\text {true }}=1.56 \mathrm{~g} / \mathrm{cm}^{3}$. The bulk density was obtained from the manufacturer, having values of $0.32 \mathrm{~g} / \mathrm{cm}^{3}$ which correspond to an initial relative density of 0.2 . Magnesium stearate (MgSt) was used as lubricant in die compaction.

\subsection{Constitutive model}

The behavior of the powder, considered as porous compressible material, is described using the density-dependent Drucker-Prager Cap (DPC) model [21]. Assuming the material is isotropic, the model consists of three different parts: A shear failure surface representing shearing flow, a cap surface representing an inelastic hardening for

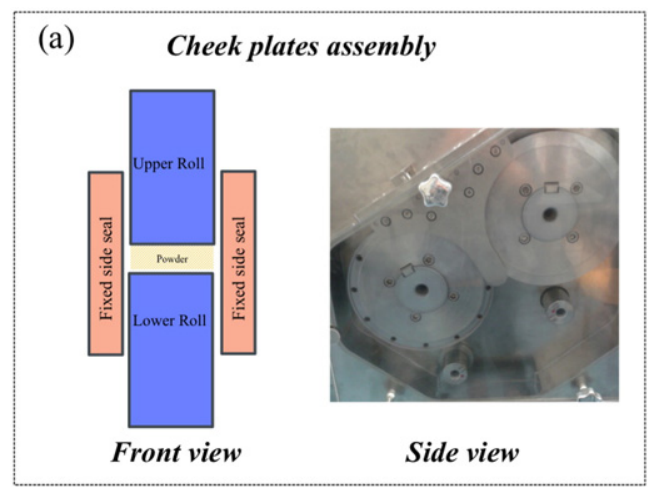

plastic compaction and a transition zone between the two surfaces, providing smooth surface to avoid singularities in the modeling (Fig. 2.). The cap surface serves two main purposes. It bounds the yield surface in pure hydrostatic compression and controls the volume dilatancy when the material yields in shear [22].

Experimental calibration of the DPC model for pharmaceutical [23-28], metallic [29,30] and ceramic [31] powders were extensively conducted in previous studies. The Drucker-Prager shear failure surface can be determined by two of the four experiments for measuring tablets strength: uniaxial tension, pure shear, diametrical compression and uniaxial compression tests. As the maximum loading values of each experiment are positioned on the shear failure line, by using two tests the shear failure line can be determined. The slope of the line represents the friction angle $\beta$, and the intersection with $\mathrm{q}$ axis represents the cohesion, $d$. The following equation represents the shear failure line, $F_{s}$ :

$$
F_{s}=q-d-p \tan \beta=0
$$

Where the hydrostatic pressure (i.e. negative mean stress), $p$ and the effective Von mises equivalent stress, $q$ are obtained from the stress tensor, $\sigma$ and defined as follows:

$$
\begin{aligned}
& p=\frac{1}{3} \operatorname{tr}(\sigma) \\
& q=\sqrt{\frac{1}{2}\left[\left(\sigma_{1}-\sigma_{2}\right)^{2}+\left(\sigma_{2}-\sigma_{3}\right)^{2}\left(\sigma_{3}-\sigma_{1}\right)^{2}\right]} .
\end{aligned}
$$

The cap yield surface is obtained by analyzing the stress state of the loading and unloading path in die compaction and written as:

$F_{c}=\sqrt{\left(p-P_{a}\right)^{2}+\left(\frac{R q}{1+\alpha-\alpha / \cos \beta}\right)^{2}}-R\left(d+P_{a} \tan \beta\right)$.

Where the density-dependent parameters $R, d$ and $\beta$ are the cap eccentricity, cohesive strength and internal friction angle, respectively. $\alpha$ is the smoothing transition constant that is used to define the smoothing transition between the shear failure surface and the cap. In this work, an arbitrary transition parameter of $\alpha=0.01$ was chosen (typically $0.01<\alpha<0.05$ ) in order to ensure avoiding numerical singularities.

As mentioned previously, in order to obtain a smoothing transition between the shear failure surface and the cap yield surface, a transition surface $F_{t}$ should be applied:

$$
F_{t}=\sqrt{\left(p-P_{a}\right)^{2}+\left[q-\left(1-\frac{\alpha}{\cos \beta}\right)\left(d+P_{a} \tan \beta\right)\right]^{2}}-\alpha\left(d+P_{a} \tan \beta\right) .
$$

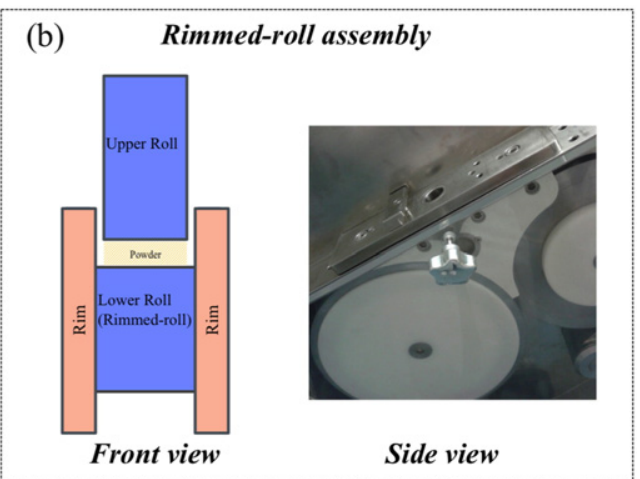

Fig. 1. Gerteis Minipactor's possible side seal assemblies a) cheek plates and b) rimmed-roll. 


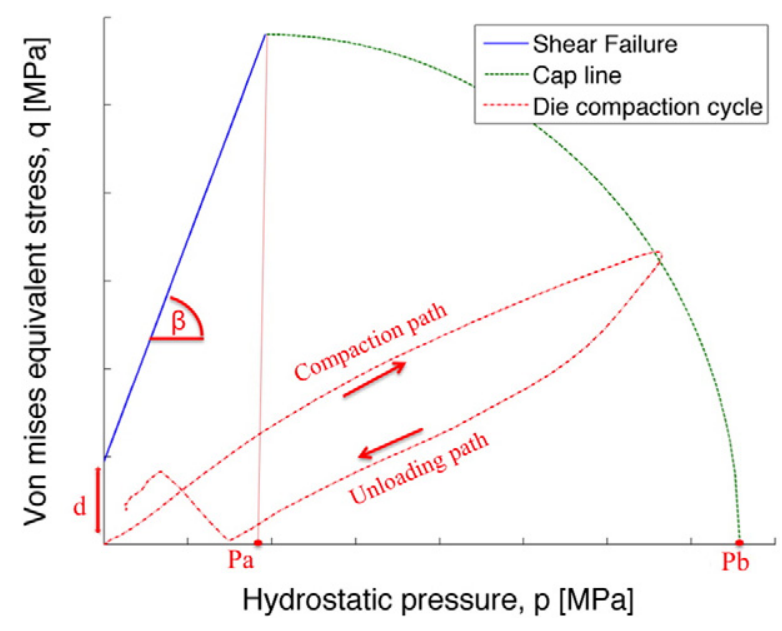

Fig. 2. The Drucker-Prager Cap yield surface model in q-p plane.

\subsubsection{Determination of elastic properties}

In this model, a simplified approach considering linear elasticity was implemented. This simplification is due to the difficulties extracting data from the non-linear behavior of the unloading in the experiment and mainly due to computational reasons, solving a linear elasticity. In fact, at low stresses and densities the elasticity is highly non-linear, whereas at high stresses and densities the elasticity shows higher linear behavior. Powder compaction can be adequately simulated by taking into account only the linear elastic part. However, simulating the ejection and extraction out of the die (or rolls) requires the non-linear contribution of the elasticity as well.

From the generalized three-dimensional Hook's law stress-strain relationship, assuming linearly elastic isotropic materials and superpositioning the strain components in a cylindrical coordinates system $(z, r, \theta)$, the strain along each axis can be written as:

$\varepsilon_{z z}=\frac{1}{E}\left[\sigma_{z z}-\nu\left(\sigma_{r r}+\sigma_{\theta \theta}\right)\right]$

$\varepsilon_{r r}=\frac{1}{E}\left[\sigma_{r r}-\nu\left(\sigma_{z z}+\sigma_{\theta \theta}\right)\right]$

$\varepsilon_{\theta \theta}=\frac{1}{E}\left[\sigma_{\theta \theta}-\nu\left(\sigma_{z z}+\sigma_{r r}\right)\right]$.

Considering the cylindrical die as rigid $\left(\varepsilon_{r r}=0\right)$ with axial symmetry conditions $\left(\varepsilon_{r r}=\varepsilon_{\theta \theta}\right.$ and $\left.\sigma_{r r}=\sigma_{\theta \theta}\right)$ Eq. (7). can be rewritten as:

$\Delta \varepsilon_{r r}=\frac{1}{E}\left[\Delta \sigma_{r r}-\nu\left(\sigma_{r r}+\sigma_{z z}\right)\right]=0$.

From Eq. (9), Poisson's ratio $\nu$ can be expressed:

$\nu=\frac{\Delta \sigma_{r r}}{\Delta \sigma_{r r}+\Delta \sigma_{z z}}=\frac{\frac{\Delta \sigma_{r r}}{\Delta \sigma_{z z}}}{\frac{\Delta \sigma_{r r}}{\Delta \sigma_{z z}}+1}$.

In the same manner and by knowing the Poisson's ratio obtained in Eq. (10), the Young's modulus E can be expressed from Eq. (6):

$\Delta \varepsilon_{z z}=\frac{1}{E}\left[\Delta \sigma_{z z}-\nu\left(\sigma_{r r}+\sigma_{r r}\right)\right]$

$E=\frac{\Delta \sigma_{z z}}{\Delta \varepsilon_{z z}} \frac{(1+\nu)(1-2 \nu)}{(1-\nu)}$
Therefore, it is needed to measure $\Delta \sigma_{r r} \Delta \sigma_{z z}$ and $\Delta \varepsilon_{z z}$ in order to obtain the elastic properties from the unloading compaction curve (Eqs. (10) and (12).).

\subsubsection{Determination of shear failure}

The shear failure line is constructed by knowing the cohesion $d$, which is the intersection with the q plane and the internal friction angle $\beta$ which is the slope of the line. First the tensile and compressive strength of the compacted powder are determined using a diametrical compression test and an unconfined uniaxial compression test. For diametrical compression, the tensile strength $\sigma_{d}$ and stress state (p-q) are defined as following:

$\sigma_{d}=\frac{2 F_{d}}{\pi D t}$

$p_{d}=\frac{2}{3} \sigma_{d} q_{d}=\sqrt{13} \sigma_{d}$

Where $F_{d}$ is the crushing force, $D$ is the tablet diameter and $t$ is the tablet thickness. For the unconfined uniaxial compression test:

$\sigma_{c}=\frac{F_{c}}{\pi D^{2}}$

$p_{c}=-\frac{1}{3} \sigma_{c} \quad q_{c}=-\sigma_{c}$.

Where $\sigma_{c}$ is the axial compression strength and $F_{c}$ is the axial compression force at the yield point. By knowing the stress state ( $\mathrm{p}-\mathrm{q})$ of both test, the cohesion and internal friction angle can be calculated:

$d=\frac{\sigma_{c} \sigma_{d}(\sqrt{13}-2)}{\sigma_{c}+2 \sigma_{d}}$

$\beta=\tan ^{-1}\left[\frac{3\left(\sigma_{c}+d\right)}{\sigma_{c}}\right]$

\subsubsection{Determination of cap surface}

From the axial $\sigma_{z z}$ and radial $\sigma_{r r}$ pressure obtained in the instrumented die, considering cylindrical $(\mathrm{r}, \theta, \mathrm{z})$-coordinates with axisymmetry conditions $\left(\sigma_{r r}=\sigma_{\theta \theta}\right)$, the mises-equivalent shear stress (Eq. (3).), and the mean stress (Eq. (2).), are simplified, respectively:

$q=\left|\sigma_{z z}-\sigma_{r r}\right|$

$p=\frac{\sigma_{z z}+2 \sigma_{r r}}{3}$.

The evolution parameter $P_{a}$ representing the hardening or softening driven by the volumetric plastic strain, the cap eccentricity $R$ and the hydrostatic pressure $P_{b}$ are obtained as follows:

$P_{a}=\frac{-3 q-4 d \tan \beta+\sqrt{9 q^{2}+24 d q \tan \beta+24 p q \tan \beta^{2}+16 q^{2} \tan \beta^{2}}}{4 \tan \beta^{2}}$

$R=\sqrt{\frac{2}{3 q}\left(p-P_{a}\right)}$

$P_{b}=P_{a}+R\left(d+P_{a} \tan \beta\right)$.

The hydrostatic pressure yield surface $P_{b}$ (Eq. (23).) defines the position of the cap and dependent on the volumetric inelastic strain $\varepsilon_{v o l}^{i n}$. 
Eqs. (21) and (22) are modified accordingly in order to introduce the smoothing transition parameter $\alpha$ [22].

$P_{b}=P_{b}\left(\varepsilon_{v o l}^{i n}\right)$

By measuring the bulk density $\rho$ of the tablet after ejection and dividing it with the initial density $\rho_{0}$ of the powder when filling the die, the inelastic volumetric strains $\varepsilon_{v o l}^{i n}$ can be calculated:

$\varepsilon_{v o l}^{i n}=\ln \left(\frac{\rho}{\rho_{0}}\right)$

\subsection{Tablet compaction}

Calibrating the DPC model requires the preparation of tables in different manners. For obtaining the elastic and the cap properties, a fully instrumented press is necessary. For the shear failure line, a simple compaction press can be used, however, certain important aspects must be kept. According to Doremus et al.[32], for the diametrical compression test, it is important to ensure that failure arises from tensile fractures originating at the center of the specimen. To achieve this, the diametrical compression test must be carried out for tablets with aspect ratio $H / D \leq$
0.25 , where $H$ is the height and $D$ is diameter of the specimen. For the axial compression test, in order to ensure the failure does not cross the two ends of the specimen, aspect ratio $(H / D)$ of specimen must equal or larger than 2.0 .

It is important to mention that the aspect ratios may vary for different materials and are only given as guidelines. Moreover, producing tablets with large heights may not sufficiently compact the powder to a solid dosage form, thus making it difficult to achieve large aspect ratios. Therefore, it is also necessary to observe and ensure that the desired failure path obtained.

\subsubsection{Tablet compaction for elastic and cap properties}

The die compaction cycles curves for different relative densities where obtained by a fully instrumented eccentric uniaxial press (Frogerais OA, France). The press is instrumented with five sensors that allow the measurement of the displacements of the upper and lower punches, the applied axial pressure $\sigma_{u}$, the transmitted axial pressure to the lower punch $\sigma_{l}$ and the radial stress on the die wall $\sigma_{r}$. The die used was a fixed cylindrical die of $11.28 \mathrm{~mm}$ of diameter and $10 \mathrm{~mm}$ of height. First, the upper punch is displaced downward, applying pressure on the powder and later the tablets are ejected out of the die by the lower punch. The tablets were prepared by automatically filling a powder mass of $0.305 \pm 0.010 \mathrm{~g}$ into the die and
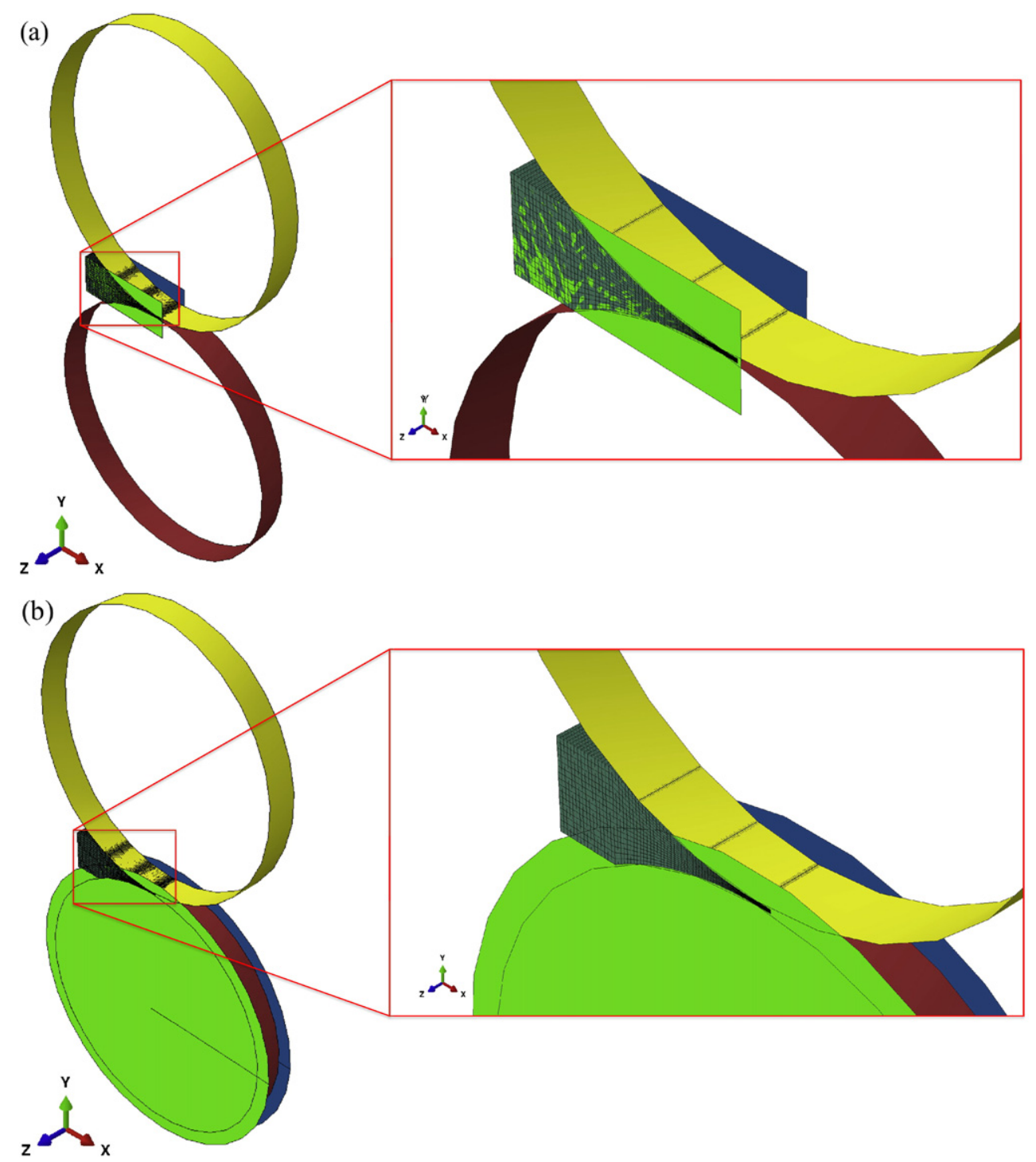

Fig. 3. FE models of roll compactor with a) cheek plates and b) rimmed-roll. 
compacting different predefined set of displacements ( 4.5 to $7.4 \mathrm{~mm}$ ) which corresponds to a set of maximum pressures (6 to $180 \mathrm{MPa}$ ), obtaining a range of relative densities (0.38 to 0.91). During the compaction process, the pressures and displacements of the upper and lower punches as well as the radial stress on the die were recorded. For each displacement set, a total of ten tablets were produced, disregarding the first and last tablets data and storing the mean values of the other eight tablets.

\subsubsection{Tablet compaction for shear failure properties}

The shear failure line parameters of cohesion $d$ and friction angle $\beta$ were calibrated using diametric and unconfined uniaxial compression tests and utilizing Eqs. (17) and (18). In order to minimize the density gradient, the specimens for diametrical compression and uniaxial compression test were prepared by lubricating the die tooling. For diametrical compression test, cylindrical flat tablets were prepared by filling a powder mass of $0.350 \pm 0.005 \mathrm{~g}$ into the die and compacting at seven different pressures (from 10 to $120 \mathrm{MPa}$ ), varying the compacted tablets thickness between 2.6 to $4.8 \mathrm{~mm}$ (resulting in relative densities of 0.46 to 0.85 ). Tablets for the compression test where produced using a cylindrical die of $11.28 \mathrm{~mm}$ of diameter and $90 \mathrm{~mm}$ of height. The aspect ratio $(H / D)$ of 2.0 was obtained by compacting the tablet to a final height of $22 \mathrm{~mm}$ with varying the filling powder mass in order to obtain a range of 0.31 to 0.9 relative densities. For repeatability, in both cases, the mean of three measurements was used for each desired relative density.

(a)
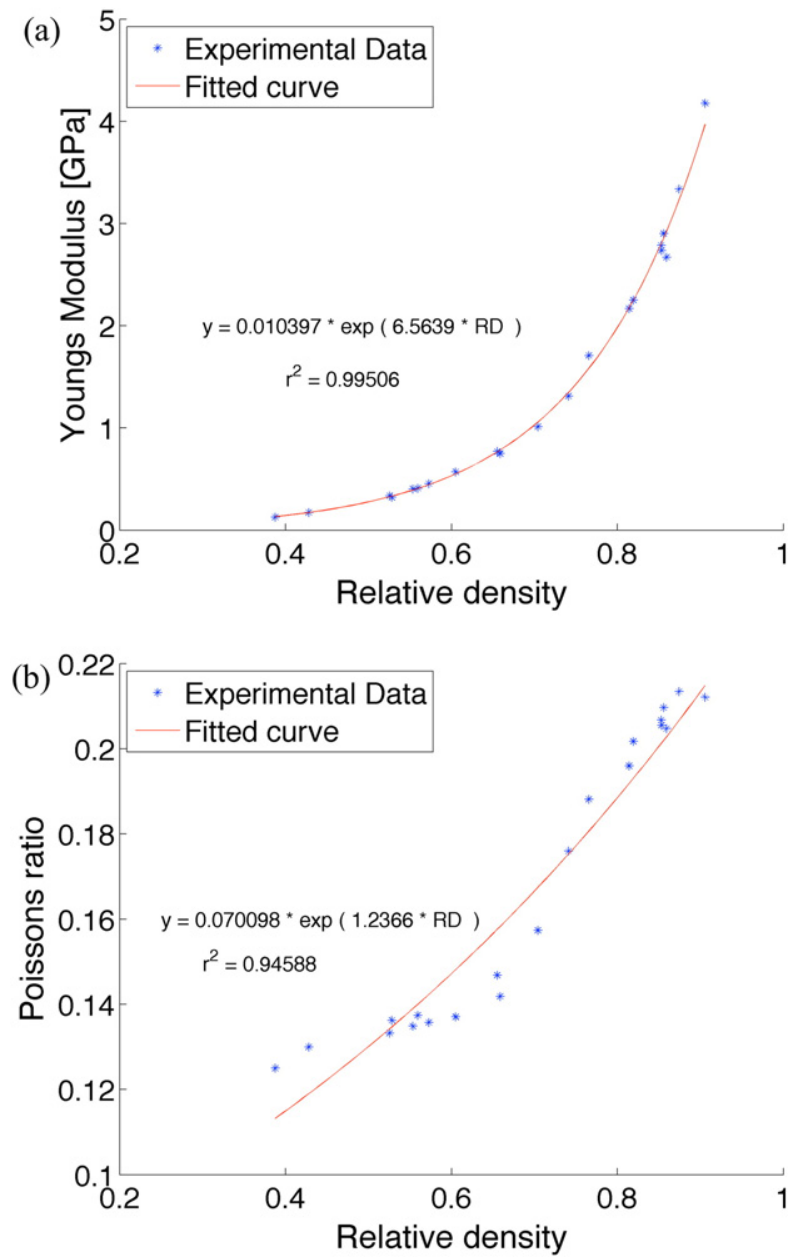

Fig. 4. Elastic properties a) Young's Modulus, E and b) Poisson's ratio, $\nu$.

\subsection{FEM models}

In this work, FEM is used to understand and predict the roll compaction process by obtaining the magnitudes and directions of stresses, strains and velocities. The FEM models were solved as a steady-state problem using arbitrary Lagrangian-Eulerian (ALE) adaptive meshing in Abaqus/Explicit v6.14. The ALE adaptive mesh domain for steadystate problems is used to model material flowing through the mesh, consist of two Eulerian boundary regions (inflow and outflow), connected by Lagrangian or Sliding boundary regions[28]. An important aspect in solving steady-state problems is to follow the system and ensure reaching the steady-state condition. A history output for roll force and torque was obtained and plotted to validate the convergence. The density-dependent behavior described by the DPC model is implemented by an external user-defined VUSDFLD Fortran subroutine code. The inlet material density was set to be the tapped powder density as a result of the screw feeding. The Avicel PH 101 tapped density is about $0.47 \mathrm{~g} / \mathrm{cm}^{3}$ which corresponds to an initial relative density of 0.3 .

First step in creating a Finite Elements (FE) model is to represent the geometry of the desired roll compactor. In the case of Gerteis Minipactor, the rolls diameter and width are $250 \mathrm{~mm}$ and $25 \mathrm{~mm}$ respectively and defined as analytic rigid surfaces. It is important to mention that the rolls here are smooth, rather than knurled in the experiment. Knurled rolls increases the complexity and the non-linearity of such simulations and are only represented by higher friction coefficient between the powder and the rolls. Once sketching the press dimensions, the region between the rolls is discretized and meshed using C3D8R threedimensional continuum reduced integration elements. The smallest gap where the powder in contact under the rolls needs to be fixed and predefined as $1.5 \mathrm{~mm}$ gap. For the cheek plates case, two analytic rigid
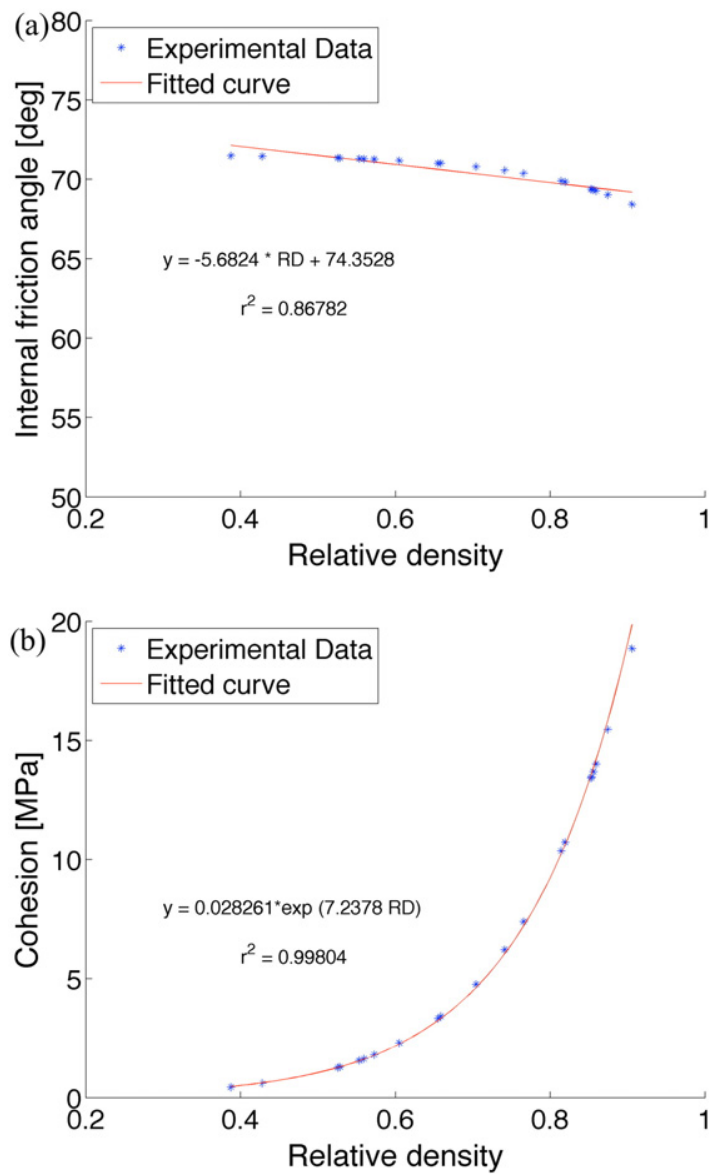

Fig. 5. Shear failure parameters a) internal friction angle, $\beta$ and b) cohesion, $d$. 
side surfaces bounding the mesh between the rolls. For the rimmed-roll case, the rim with diameter of $275 \mathrm{~mm}$ is integrated with the bottom roll and defined as analytic rigid surface as well. The FE models for both roll compactor sealing systems designs are visualized in Fig. 3. It is important to mention that due to the unsymmetry of the rimmed-roll sealing system assembly, both FE model's geometry was constructed fully without taking into account symmetry conditions, which are usually applied to reduce computational costs.

\subsubsection{Powder-tools interaction}

The ALE method enables working both with the advantages of Lagrangian and Eulerian elements in the same part [33]. While the inlet and outlet surfaces are defined as Eulerian regions, the upper and
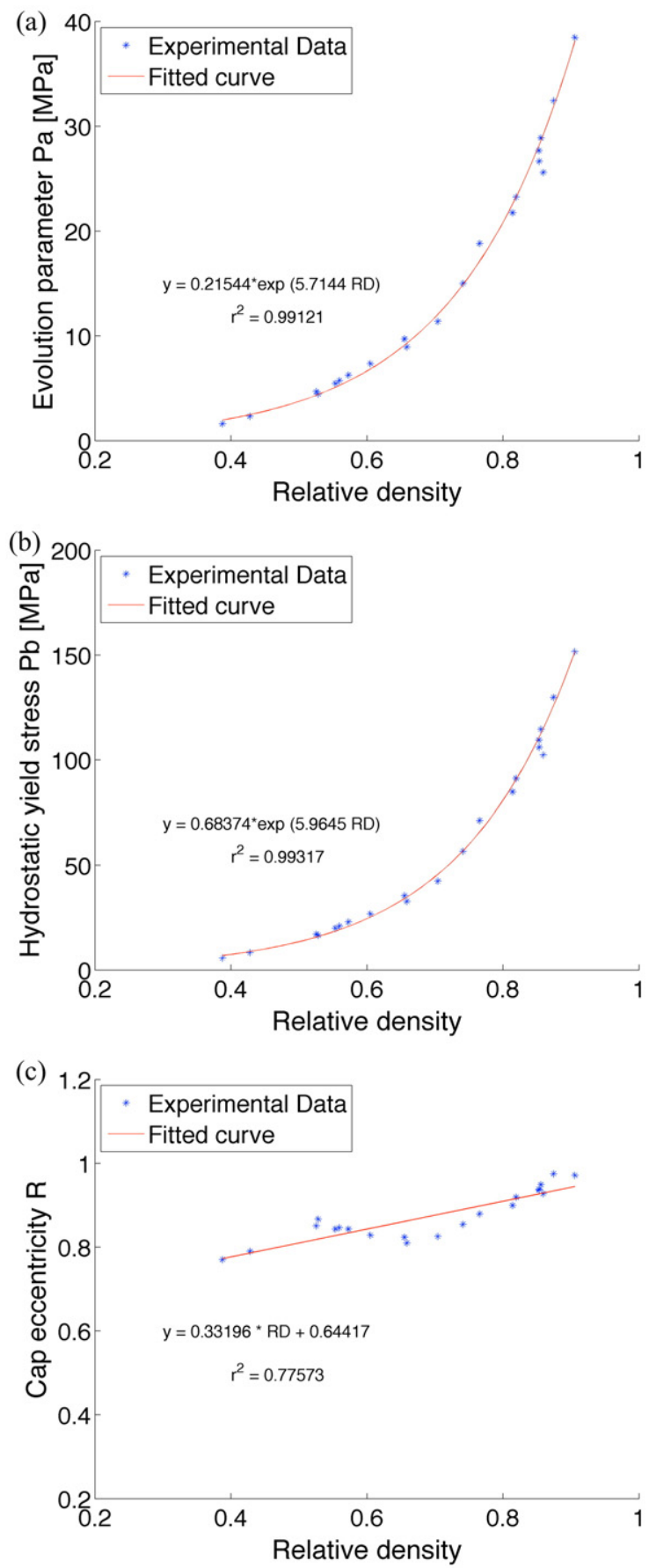

Fig. 6. Cap line parameters a) $\mathrm{Pa}, \mathrm{b}) \mathrm{Pb}$ and $\mathrm{c}) \mathrm{R}$. lower surfaces that are in contact with the roll are defined as sliding surfaces. The contact between the rigid roll surface and the sliding surface defined as surface-to-surface with a given coulomb coefficient of friction $\mu$. For numerical reasons, an ad hoc choice of constant friction coefficient was chosen. A value of $\mu=0.4$ is the most representative single value obtained experimentally for a non lubricant case [12,17]. The surfaces representing the boundary in the feeding region are defined as Eulerian regions with zero displacement boundary conditions in normal directions and spatial mesh constraint in all directions. These Eulerian boundary conditions represent a sealing system with zero friction and therefore no shear forces applied on the powder in the feeding region. The surfaces representing the contact between powder and side seals/rim rolls are defined as sliding region with spatial mesh constraint in the tangential directions. The contact between the outer surfaces representing the powder and the sealing system are defined as surface-to-surface with the same given coulomb coefficient of friction $\mu=0.4$.

\subsubsection{Boundary conditions}

In the roll compaction process, the inlet stress is dependent both on the screw and press dimensions and process parameters. In this work the inlet was simplified and defined as a constant feeding pressure of $0.2 \mathrm{MPa}$ in order to obtain the desired $4 \mathrm{kN} / \mathrm{cm}$ roll separation force. As the cross section area, shape and position of the inflow boundary are measured directly from the roll compactor and known in advance, both the material and mesh constraints must be applied. The inlet and outlet nodes were constraint in the normal direction to avoid translation in the stream wise direction and maintain a steady uniform flow. In order to improve convergence to the steady-state solution, a linear constraint equation was implemented both for the inlet and outlet nodes, constraining the material velocity to be uniform normal to the outflow. A rotational boundary condition in $z$-direction was defined based on the roll rotating velocity in the experiment, which was set to $2 \mathrm{rpm}$.

\subsection{Model validation: ribbon porosity measurement}

Ribbon samples collected from the roll compaction were analyzed for relative density values. The $2.5 \mathrm{~cm}$ wide ribbons were sectioned into rectangular pieces of approximately $0.6 \times 1 \mathrm{~cm}$. The mass of each piece was determined with a high precision balance. The ribbon relative density (RD) requires both powder true density $\left(\rho_{\text {true }}\right)$ and ribbon envelope density $\left(\rho_{e}\right)$. The envelope density of the ribbons was determined using an envelope density analyzer (Geopyc 1360, Micromeritics Instrument Corp., Norcross, GA, USA). The internal diameter tube, consolidation force and conversion factor of $25.4 \mathrm{~mm}, 51 \mathrm{~N}$ and $0.5153 \mathrm{~cm}^{3} / \mathrm{mm}$, respectively were used. Once obtaining both the true and envelope

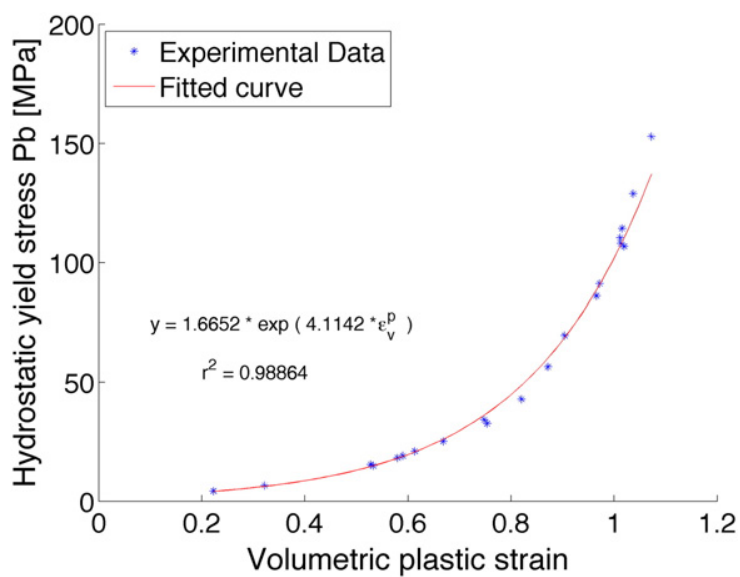

Fig. 7. Hydrostatic compressive stress, $\mathrm{Pb}$ as a function of volumetric plastic strain. 


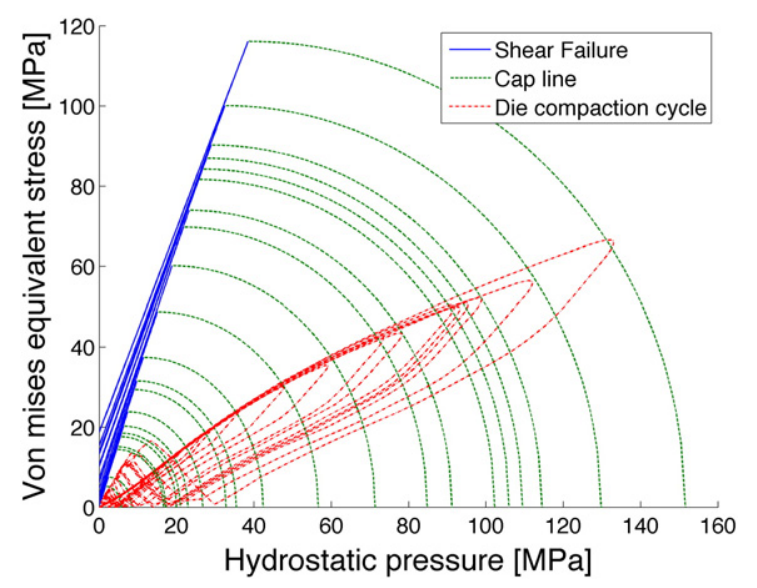

Fig. 8. Experimental iso-density Drucker-Prager Cap.

density, the sample's porosity $(P)$ and the relative density can be expressed as follows:

$R D=1-P=\frac{\rho_{e}}{\rho_{\text {true }}}$.

\section{Results and discussion}

\subsection{Experimental calibration of DPC model}

The Drucker-Prager Cap model parameters are plotted as a function of the relative density. The elastic properties obtained by analyzing the die compaction unloading curves using Eqs. (12) and (10) are plotted in Fig. 4. It can be seen the Young's Modulus is increasing exponentially from 0.08 to $7.4 \mathrm{GPa}$ in the range between the filling bulk density and a full dense material. The Poisson's ratio does not show a decisive exponential behavior, having scatter values from 0.1 to 0.24 for the same range of relative densities. The cohesion and internal friction angle are obtained from nonlinear regression fittings of the diametrical and compressive tests and plotted for the desired relative densities which the DPC model was calibrated(Fig. 5.). As the Young's Modulus, the cohesion values increases exponentially with increasing relative density. The internal friction angle shows a nonlinear behavior, with a slight decrease for low relative densities and larger for high relative densities.

The Cap line evolution parameter $\mathrm{Pa}$, hydrostatic compressive stress $P b$ and the cap eccentricity $R$, which defines the shape of the cap are plotted against the relative densities(Fig. 6.). Following the definition in Eq. (24), the hydrostatic compressive stress $P b$ is plotted as a function of the volumetric plastic strains as well(Fig. 7.).

From the obtained results, the full DPC model is plotted with different isolines, representing each relative density(Fig. 8). With the increasing relative density, the yield surface (or line in Fig. 8) expands in stress space. It can be seen that each shear failure line has a different slope and intersection with the equivalent stress axis, which are represented by the density dependent internal friction angle and cohesion, respectively, plotted in Fig. 5. The dotted lines are the die compaction curves in the $\mathrm{p}-\mathrm{q}$ plane for different relative densities.

Most of the results show a clear and decisive exponential behavior which is used to extrapolate the DPC model for the low and high relative densities. However, some results such as the cohesion and the cap eccentricity did not show such behavior and may result in a non realistic
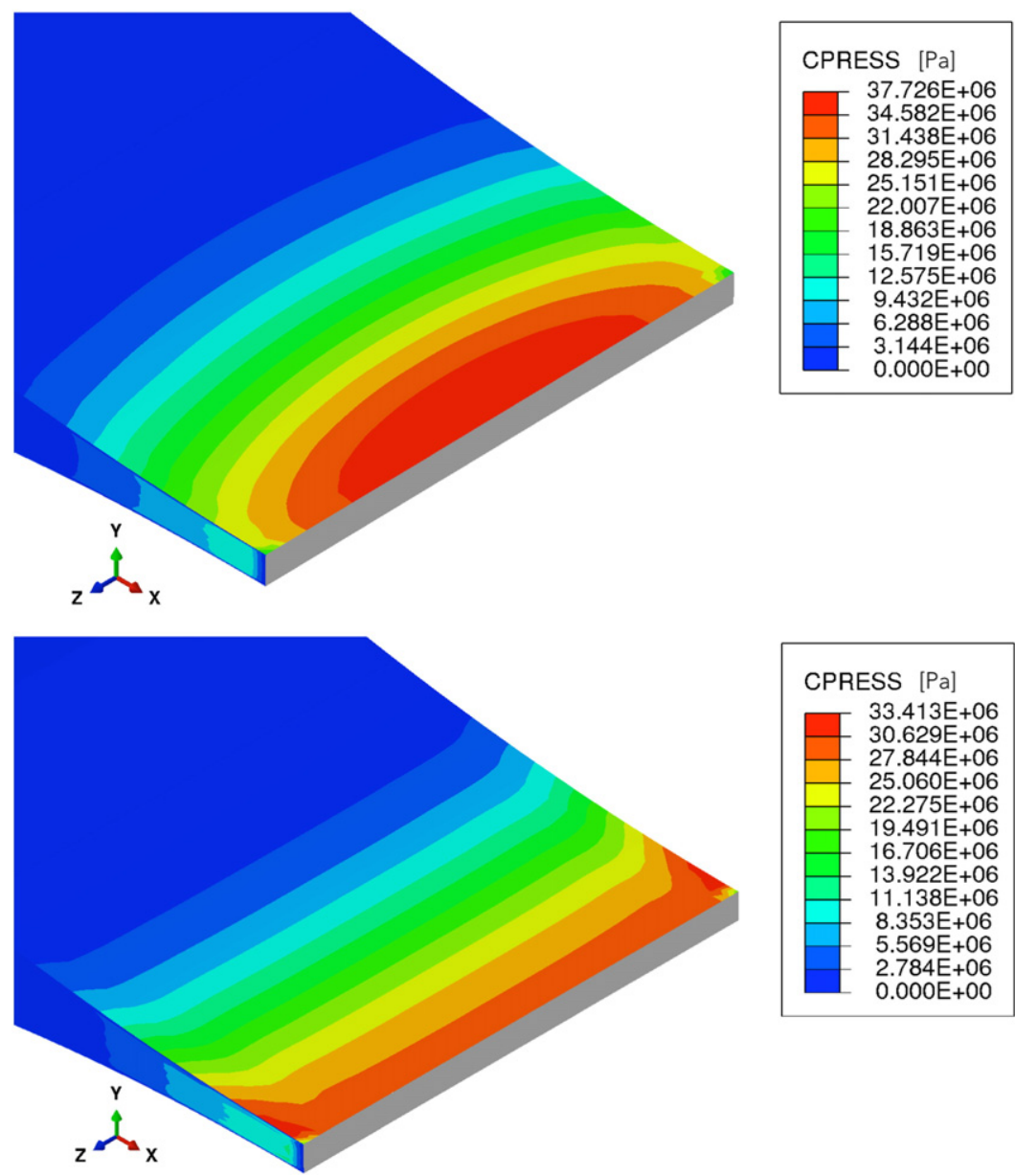

(a)

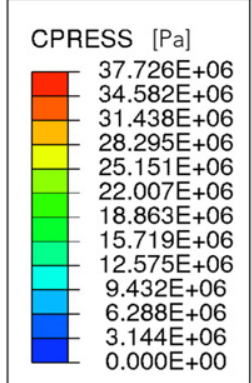

(b)

Fig. 9. Contact pressure between powder and upper roll for a) cheek plates and b) rimmed-roll. 

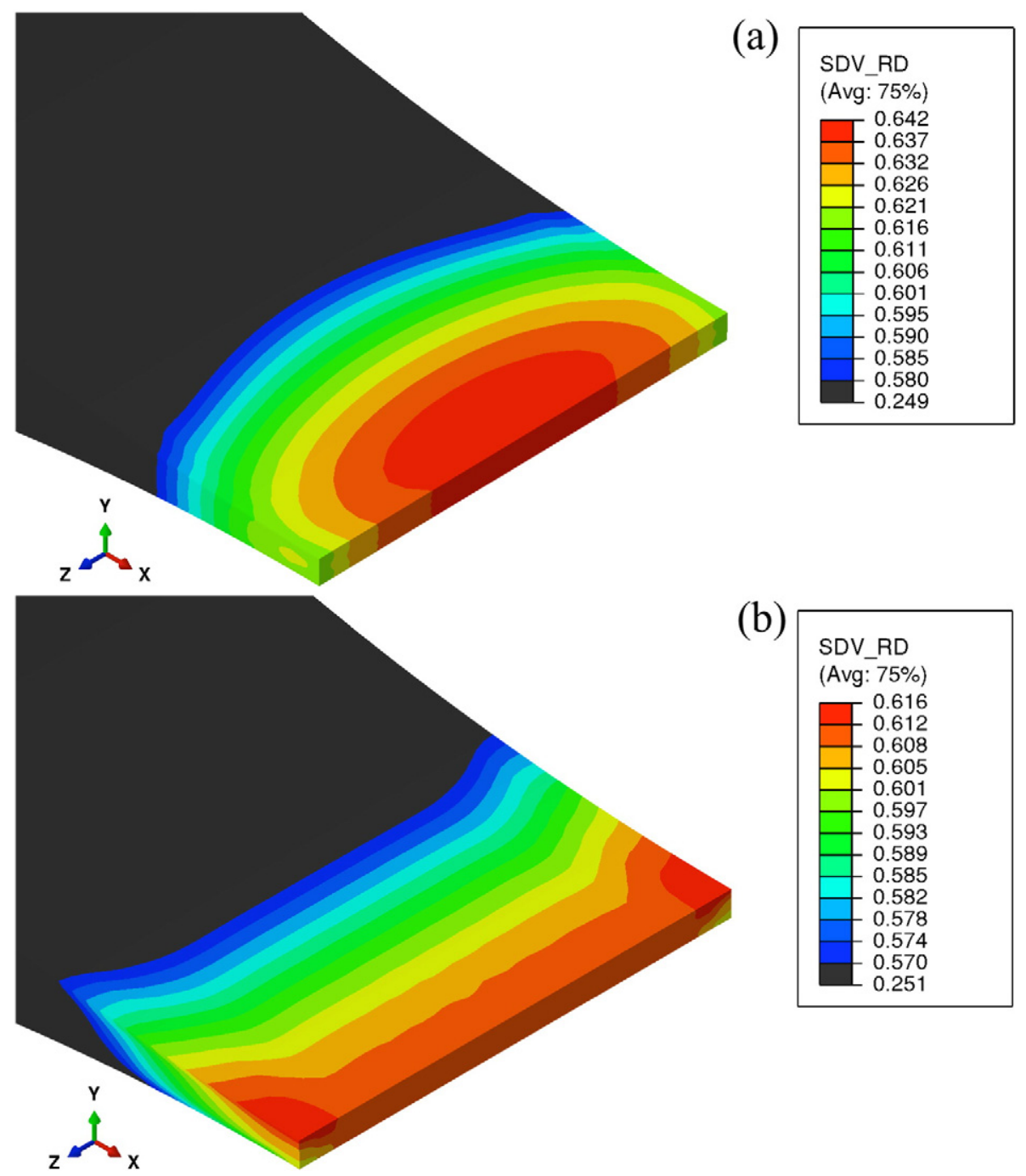

(b)

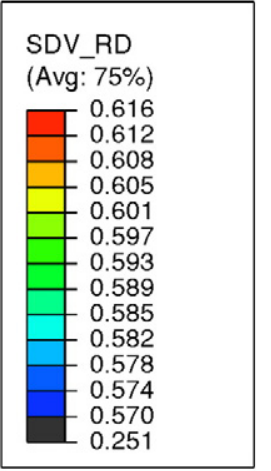

Fig. 10. Relative density for the two sealing systems a) cheek plates and b) rimmed-roll.

extrapolated data. The results show a similar behavior as in the literature which is mostly done for MCC 102 with one exceptional study on MCC 101 [22].

\subsection{Simulation results}

Once reaching a steady-state solution by obtaining a constant relative density and vertical reaction force on the roll pin, the FEM results were analyzed. A typical FEM modeling calculates stresses, strains and velocities. Due to numerical reasons, the results are obtained and plotted only for the material which is still in contact with the roll, up to the narrowest gap region. [17]. In addition, in this work, a userdefined subroutine was implemented using a state variable of the relative density, $\left(R D=R D_{0} e^{-\varepsilon_{v}^{p}}\right)$ which is calculate from the initial bulk density, $R D_{0}$ and the volumetric plastic strain, $\varepsilon_{v}^{p}$.

Comparing both cases of cheek plates and rimmed-roll assemblies, the upper roll contact pressure distribution is visualized in Fig. 9. First, it can be seen that for both sealing system designs, the contact pressure increases with the rolling direction until reaching a maximum value just before the narrowest gap. The contact pressure varies between 25 to $37 \mathrm{MPa}$ and 29 to $33 \mathrm{MPa}$ along the ribbon's width for the cheek-plates and rimmed-roll assemblies, respectively. The state variable relative density distribution of the powder between the rolls is visualized in Fig. 10. The relative density varies between 0.59 to 0.64 and 0.60 to 0.62 along the ribbon's width for the cheek-plates and rimmed-roll assemblies, respectively.

Results clearly show the effect of the cheek plates, causing a nonuniform roll pressure and density distribution with the highest values in the middle and the lowest in the edges. The powder was not adequately and uniformly delivered to the gripping and compaction zone. This occurred as the cheek plates preventing the powder flow and causes an uneven compaction across the ribbon's width, resulting in lower densification at the edges and higher at the middle of the produced ribbon.

On the contrary to the cheek plates, the resultant pressure and density distribution with the rimmed-roll obtained higher values in the edges than in the middle and overall a more uniformly distributed. The rimmed-roll holds the powder mass and transporting it into the gripping zone between the rolls, protecting it from the adverse effect of the cheek plates. Additionally, The inner walls of the rims increase the contact area between the powder and the rolls, which increases the frictional drive in the edges.

\subsection{Validation}

As mentioned previously (Section 1), the ribbon's density is one of the critical quality parameter of roll compaction process and therefore used for validating the FEM models. To verify the results, the simulations are compared with experimental measured values and plotted in Fig. 11. The results show overall the same tendency as the experimental 

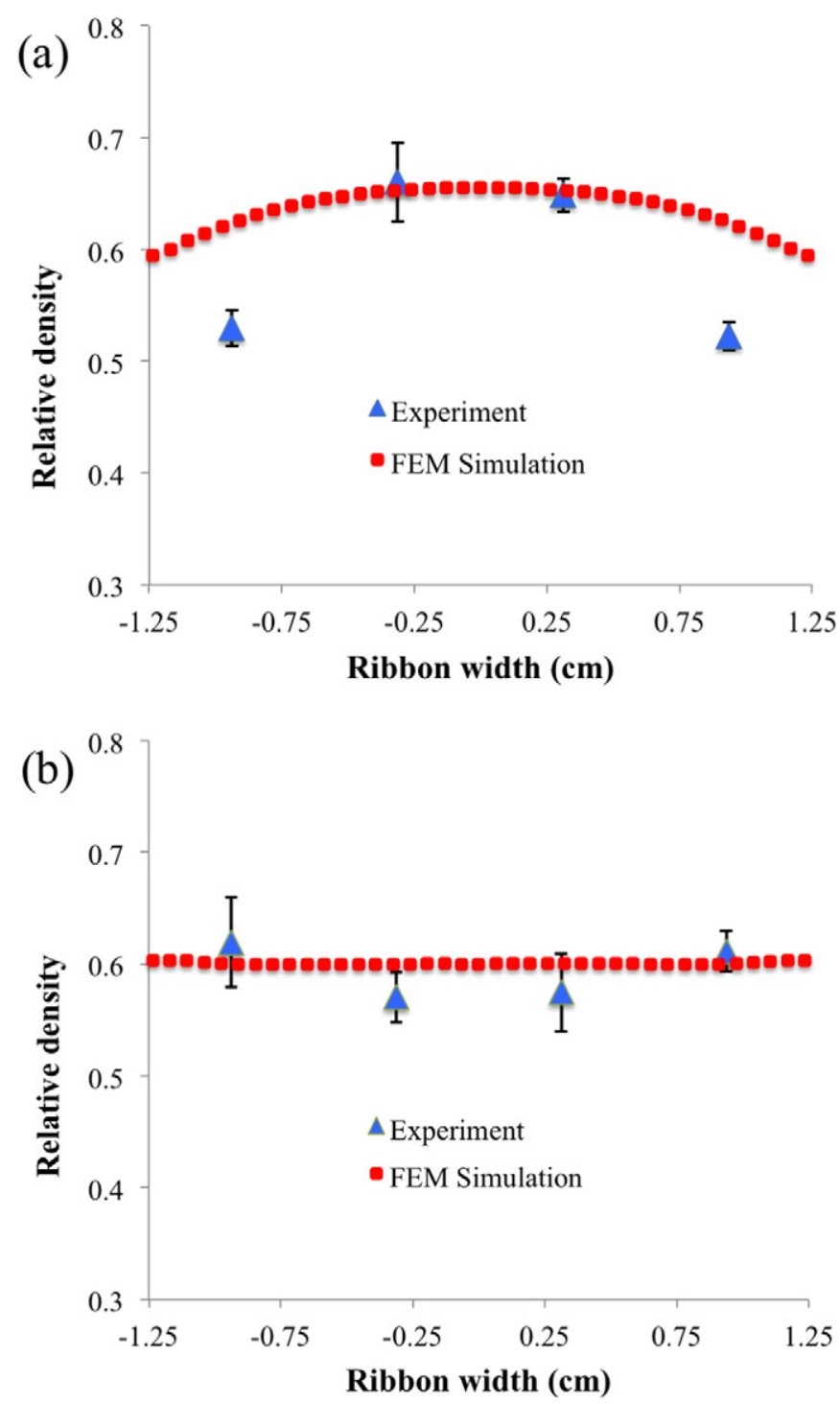

Fig. 11. Ribbon's density distribution for a) cheek plates and b) rimmed-roll.

measurements with an overestimation of ribbon density on the sides for cheek plates sealing system. On the other hand, for the cheek plates' case, the results show agreement with the results obtained in the literature for different powder [17].

The difference between the FEM and experimental results for the cheek plates' case may be explained by the non constant nature of friction coefficient which has a direct impact on the density gradient. However, for high contact forces and relative densities, the friction coefficient tends to asymptote to a constant value [34]. The difference in results may also be explained by the loss of powder occurs in the roll compaction process, whereas the FEM model considers mass conservation. The problem of leakage from the sides is especially significant for fine $\left(d_{50}=50_{\mu \mathrm{m}}\right)$ powders such as the MCC 101. Moreover, cheek plates may also have a negative effect on the ribbon with fractured or incomplete compacted edges. Therefore, it can be noted that the ribbon's non-uniformity properties for the cheek plates sealing system was mostly dominant by the loss of powder from the sides, rather than the effect of wall friction.

\section{Conclusions}

In this work, a 3D Finite Elements Method (FEM) modeling is used to analyze the roll compaction process and the effect of sealing system designs on the compacted ribbon's density distribution. The FEM simulation results clearly show the effect of the cheek plates, causing a nonuniform roll pressure and density distribution with the highest values in the middle and the lowest in the edges. Whereas, the resultant pressure and density distribution with the rimmed-roll obtained higher values in the edges than in the middle and overall a more uniformly distributed. The results show agreement with experimental measurements and present the same tendency as in the literature for different powders. The inconsistency between FEM and experimental results may be explained by the assumptions made in the FE models and considering a conservation of mass without loss of powder.

These results demonstrate the ability of FEM modeling to provide insight and better understanding of the roll compaction process. FEM modeling may also be used in improving the quality of ribbons with new designs.

\section{Acknowledgments}

This project has received funding from the European Union's Seventh Framework Programme for research, technological development and demonstration under grant agreement No. 316555. The authors would like to thank Prof. Peter Kleinebudde and Mrs. Ana Pérez Gago from Düsseldorf University for providing scientific, and technical support and recommendations using the Gerteis roll compactor. The authors also thank Dr. Gavin Reynolds and Dr. Andreja Mirtic from AstraZeneca,UK for giving access to the GeoPyc in order to validate this work.

\section{References}

[1] P. Kleinebudde, Roll compaction/dry granulation: pharmaceutical applications, Eur. J. Pharm. Biopharm. 58 (2004) 317-326, http://dx.doi.org/10.1016/j.ejpb.2004.04. 014.

[2] D.M. Parikh, Handbook of Pharmaceutical Granulation Technology, 1997 532, http:// dx.doi.org/10.1201/9780849354953.ch17.

[3] I. Akseli, S. Iyer, H.P. Lee, A.M. Cuitiño, A quantitative correlation of the effect of density distributions in roller-compacted ribbons on the mechanical properties of tablets using ultrasonics and X-ray tomography, AAPS PharmSciTech 12 (3) (2011) 834-853, http://dx.doi.org/10.1208/s12249-011-9640-z.

[4] A.M. Miguélez-Morán, C.Y. Wu, H. Dong, J.P.K. Seville, Characterisation of density distributions in roller-compacted ribbons using micro-indentation and X-ray micro-computed tomography, Eur. J. Pharm. Biopharm. 72 (1) (2009) 173-182, http://dx.doi.org/10.1016/j.ejpb.2008.12.005.

[5] H. Lim, V.S. Dave, L. Kidder, E. Neil Lewis, R. Fahmy, S.W. Hoag, Assessment of the critical factors affecting the porosity of roller compacted ribbons and the feasibility of using NIR chemical imaging to evaluate the porosity distribution, Int. J. Pharm. 410 (1-2) (2011) 1-8, http://dx.doi.org/10.1016/j.ijpharm.2011.02.028.

[6] M. Khorasani, J. Amigo, J. Sonnergaard, P. Olsen, P. Bertelsen, J. Rantanen, Visualization and prediction of porosity in roller compacted ribbons with near-infrared chemical imaging (NIR-CI), J. Pharm. Biomed. Anal. 109 (2015) 11-17, http://dx.doi.org/10. 1016/j.jpba.2015.02.008.

[7] J.C. Cunningham, D. Winstead, A. Zavaliangos, Understanding variation in roller compaction through finite element-based process modeling, Comput. Chem. Eng. 34 (7) (2010) 1058-1071, http://dx.doi.org/10.1016/j.compchemeng.2010.04.008.

[8] N. Souihi, G. Reynolds, P. Tajarobi, H. k. Wikström, G. Haeffler, M. Josefson, J. Trygg, Roll compaction process modeling: transfer between equipment and impact of process parameters, Int. J. Pharm. 484 (2015) 192-206, http://dx.doi.org/10.1016/j. ijpharm.2015.02.042.

[9] S.E. Funakoshi, Y., Asogawa T., Use of a novel roller compactor with a concavoconvex roller pair to obtain uniform compaction pressure, Drug Dev. Ind. Pharm. 3 (6) (1977) 555-573.

[10] R.T. Dec, A. Zavaliangos, J.C. Cunningham, Comparison of various modeling methods for analysis of powder compaction in roller press, Powder Technol. 130 (2003) 265-271, http://dx.doi.org/10.1016/S0032-5910(02)00203-6.

[11] J.C. Cunningham, Experimental Studies and Modeling of the Roller Compaction of Pharmaceutical Powders, Strain(July) 2672005.

[12] A. Michrafy, H. Diarra, J.A. Dodds, M. Michrafy, L. Penazzi, Analysis of strain stress state in roller compaction process, Powder Technol. 208 (2011) 417-422, http:// dx.doi.org/10.1016/j.powtec.2010.08.037.

[13] J.R. Johanson, A rolling theory for granular solids, J. Appl. Mech. 32 (4) (1965) 842-848, http://dx.doi.org/10.1115/1.3627325.

[14] T.V. Karman, Contribution to the theory of rolling, Math. Mech. 5 (2) (1925) $139-141$.

[15] V.P. Katashinskii, Analytical determination of specific pressure during the rolling of metal powders (In Russian), Sov. Powder Met. Ceram. 10 (6) (1986) 765-772. 
[16] A. Michrafy, H. Diarra, J.A. Dodds, M. Michrafy, Experimental and numerical analyses of homogeneity over strip width in roll compaction, Powder Technol. 206 (1-2 (2011) 154-160, http://dx.doi.org/10.1016/j.powtec.2010.04.030.

[17] A.R. Muliadi, J.D. Litster, C.R. Wassgren, Validation of 3-D finite element analysis for predicting the density distribution of roll compacted pharmaceutical powder, Powder Technol. 237 (2013) 386-399, http://dx.doi.org/10.1016/j.powtec.2012.12.023.

[18] W. Wang, A. Zavaliangos, J. C. Cunningham, The effect of side constraint in rolling compaction of powder, Proceedings of the 2003 International Conference on Powder Metallurgy and Particulate Materials.

[19] J.-H. Yoon, S.H. Jeong, Material properties and compressibility using Heckel and Kawakita Equation with commonly used pharmaceutical excipients, J. Pharm. Investig. 40 (4) (2010) 237-244.

[20] H. Hiestand, D. Smith, Indices of tableting performance, Powder Technol. 38 (2) (1984) 145-159, http://dx.doi.org/10.1016/0032-5910(84)80043-1.

[21] S. Helwany, Applied Soil Mechanics with ABAQUS, 2007.

[22] L.H. Han, J.a. Elliott, a.C. Bentham, a. Mills, G.E. Amidon, B.C. Hancock, A modified Drucker-Prager Cap model for die compaction simulation of pharmaceutical powders, Int. J. Solids Struct. 45 (2008) 3088-3106, http://dx.doi.org/10.1016/j.jjsolstr. 2008.01.024.

[23] a. Michrafy, D. Ringenbacher, P. Tchoreloff, Modelling the compaction behaviour of powders: application to pharmaceutical powders, Powder Technol. 127 (2002) 257-266, http://dx.doi.org/10.1016/S0032-5910(02)00119-5.

[24] I. Sinka, J. Cunningham, a. Zavaliangos, The effect of wall friction in the compaction of pharmaceutical tablets with curved faces: a validation study of the Druckerâ €“Prager Cap model, Powder Technol. 133 (1-3) (2003) 33-43, http://dx.doi.org/ 10.1016/S0032-5910(03)00094-9.

[25] J.C. Cunningham, I.C. Sinka, a. Zavaliangos, Analysis of tablet compaction. I Characterization of mechanical behavior of powder and powder/tooling friction, J. Pharm. Sci. 93 (8) (2004) 2022-2039, http://dx.doi.org/10.1002/jps.20110.
[26] K. Lamarche, D. Buckley, R. Hartley, F. Oian, S. Badawy, Assessing materials' tablet compaction properties using the Drucker â€“"Prager Cap model, Powder Technol. 267 (2014) 208-220, http://dx.doi.org/10.1016/j.powtec.2014.06.050.

[27] A. Krok, M. Peciar, R. Fekete, Numerical investigation into the influence of the punch shape on the mechanical behavior of pharmaceutical powders during compaction, Particuology http://dx.doi.org/10.1016/j.partic.2013.12.003.

[28] P. U. Dassault Systems, ABAQUS Documentation.

29] B. Zhang, M. Jain, C. Zhao, M. Bruhis, R. Lawcock, K. Ly, Experimental calibration of density-dependent modified Drucker-Prager/Cap model using an instrumented cubic die for powder compact, Powder Technol. 204 (1) (2010) 27-41, http://dx. doi.org/10.1016/j.powtec.2010.07.003.

[30] J. Almanstötter, A modified Druckerâ€“Prager Cap model for finite element simulation of doped tungsten powder compaction, Int. J. Refract. Met. Hard Mater. 50 (2015) 290-297, http://dx.doi.org/10.1016/j.ijrmhm.2015.02.005.

[31] I. Aydin, B.J. Briscoe, K.Y. Åžanlitürk, The internal form of compacted ceramic components: a comparison of a finite element modelling with experiment, Powder Technol. 89 (3) (1996) 239-254, http://dx.doi.org/10.1016/S0032-5910(96)03188-9.

[32] M.P. Doremus, J. Prado, Model Input data - Failure, Modelling of Powder Die Compaction, Springer-Verlag, London 2008, pp. 95-103, http://dx.doi.org/10.1007/ 978-1-84628-099-3.

[33] D.J. Benson, S. Okazawa, Contact in a multi-material Eulerian finite element formulation, Comput. Methods Appl. Mech. Eng. 193 (2004) 4277-4298, http://dx.doi.org/ 10.1016/j.cma.2003.12.061.

34] a. Michrafy, J.a. Dodds, M.S. Kadiri, Wall friction in the compaction of pharmaceutica powders: measurement and effect on the density distribution, Powder Technol. 148 (1) (2004) 53-55, http://dx.doi.org/10.1016/j.powtec.2004.09.021. 